\title{
EDITORIAL
}

\section{Sexual and reproductive health care issues in nurse practitioner preparation: The dialogue continues}

\begin{abstract}
As nurse practitioners (NPs) assume an ever increasing share of the primary care services provided in the U.S. the skills and education of the NP workforce will be tested and carefully scrutinized. Our history thus far has demonstrated we are more than capable to assume this increased workload and to examine our own preparedness. One of the reasons NPs have fared well is our model of education - advanced practice skills built on evidence-based nursing practice; added to that is our willingness to explore new and better options for workforce preparedness. Those qualities are artfully explored in the following letters. The original guest editorial (Berg, Woods, Kostas-Polston, $\delta$ Johnson-Mallard, 2014) raised the question of a need to expand NP education in creative ways to address increasingly complex care needs of men and women with sexual and reproductive health issues, which prompted a thoughtful response from a reader and in turn, a response from the original authors. Our ability and willingness to engage in dialogue is the way forward to meeting the challenges we all face in education and clinical practice.
\end{abstract}

Charon A Pierson, PhD, GNP, FAAN, FAANP, Editor-in-Chief

\section{To the Editor:}

After reading the January 2014 guest editorial I was moved to respond. As a specialist in men's sexual and reproductive health (SRH), I approached this document with enthusiasm, but I quickly became frustrated. Throughout the piece the authors suggest that SRH care for both women and men should be a priority in nurse practitioner (NP) curricula. But a careful inspection of this editorial exposes the fact that the authors' presentation of concepts throughout this document makes SRH synonymous with women's SRH. While disappointing, this is not unanticipated, given that this was a document produced by the Women's Health Expert Panel of the American Academy of Nursing.

But the editorial suggests that there will be an evaluation to assess the adequacy of preparation of NPs to address the SRH needs of both men and women. Because these authors question whether or not present primary care-oriented education for NPs includes sufficient content to prepare them for SRH care, this particular point needs to be belabored, especially as the authors conclude "we cannot be certain that NPs are prepared to address women's and men's SRH needs in primary care settings" (Berg, Woods, Kostas-Polston, \& Johnson-Mallard, 2014 , pg. 4). In the case of men, the answer is clearly no, and needs no further investigation. Despite the fact that these authors acknowledge the decline in programs preparing women's health NPs, let it not be forgotten that there has never been a parallel program to prepare men's health NPs. This could be viewed as a lack of parity in NP preparation and focus, based on gender. This disadvantages men who have SRH issues, and Auerbach, et al. (2012) acknowledge that "men's SRH ... is largely absent from APRN curricula and clinical training plans" (pg. 41).

Furthermore these authors suggest that the burden of SRH care should fall on primary care practitioners, stating "it is no longer feasible or desirable to provide SRH care in a fragmented fashion that necessitates women and men seeing multiple providers" (Berg, et al., 2014, pg. 3). Issues of sexual health and reproduction are not always inclusive. Other comorbidities and alterations in health are referred to specialist providers, in order to take advantage of their knowledge and expertise, to insure high-quality care. This should be no different for SRH issues. In many instances this is already the standard and is a necessity given the aforementioned lack of preparation in generalist NP programs.

The inclusion of SRH care education in the curriculum and training of NPs should not be an issue for debate. What must be an issue is the guarantee that there is more than an afterthought given to how this will be addressed for men. The Royal College of Nursing and WHO competencies mentioned in the editorial are skewed significantly to the needs of women, but offer a place to begin. The concept of starting a residency program for NPs to advance their sexual health knowledge and clinical expertise is an excellent suggestion, as long as it also offers the opportunity for specialization in men's sexual health and/or women's sexual health.

The authors of this editorial missed an opportunity to inform readers about, and encourage partnership with, 
established organizations that provide ongoing education regarding sexual health and reproduction issues. Organizations such as Sexual Medicine Society of North America (SMSNA), American Society for Reproductive Medicine (ASRM) and the International Society for the Study of Women's Health (ISSWSH) offer high-quality conferences on varied sexual and reproductive health topics and welcome all providers with an interest in SRH.

Sexuality and reproductive health are clearly topics worthy of the attention of primary care NPs, and should be included in NP curricula and clinical training. But as increasing numbers of men and women seek care for these quality of life issues, we must be careful to acknowledge our own experience and preferences while working to define these curricula.
Respectfully,

Susanne Quallich, ANP-BC, NP-C, CUNP Division of Andrology and Urologic Health

Department of Urology

University of Michigan Health System

\section{A response from the Women's Health Expert Panel (WHEP) of the American Academy of Nursing (AAN)}

Susanne Quallich raises some important issues in her response to our guest editorial. We wish to address the issues of health professional education in population and/or specialty practice and specifically the challenges faced by nurse practitioner (NP) educators balancing accreditation and certification requirements.

As background, the evolution of women's health as a specialty was marked by decades of grassroots activism, public policy, and government institutions making women's health a priority in education, policy, research, and health care that prompted change in health professional education. This attention to advancing women's health and services was never meant to deter the advancement of men's sexual health. We refer you to two papers, also from the AAN WHEP, in which we analyze several recent federal and international policy shaping reports and recommend an expanded research agenda from a grounded nursing perspective (e.g., development and testing of gender-sensitive interventions) and health service recommendations to advance gendersensitive and life span prevention services coordinated within a primary healthcare system (primary care and public health; Berg, Taylor, \& Woods, 2013; Shaver, Olshansky, \& Woods, 2013). Given the challenges inherent in delivering gender-sensitive services to women and men, the opportunities to provide optimal health care to both men and women depends on the quality of emerging science that undergirds practice.
Beginning in the 1970s, nurses (many who were NPs) in collaboration with other disciplines provided leadership to advance new conceptual frameworks for women's health research, practice, and education, put women at the center of the inquiry, integrated feminist theory in the frameworks, employed theoretical models of health and illness specific to women, and emphasized health, holism, person-environment relationships, and social determinants of health (Andrist \& MacPherson, 2001; McBride, 1993; Olesen, Taylor, Ruzek, \& Clarke, 1997; Pender, 1987; Shaver, 1985; Taylor \& Woods, 1996; Woods, 1994). These models conceptualized women's health care as a specialty. Specialization in the health professions refers to a type of practice guided by a focused body of knowledge and involves completing specific educational requirements, earning credentials that signify the specialized status of the practitioner, and ensuring continuing competency in the specialty as required to maintain a license to practice in the advanced practice specialty.

But as accreditation and credentialing programs developed for NP education and certification, the focus was on standards and competencies for population-based care (e.g., pediatrics, women, family, adult, geriatrics) resulting in an overlap of specialty and population standards (APRN Joint Dialogue Group Report, 2008). However, we have only to look to global health systems for a rational and tested model that integrates sexual and 
reproductive health specialization for men and women across the life span with a special emphasis on adolescents delivered by primary care and public health professionals (Faculty of Sexual and Reproductive Healthcare, Royal College of Obstetricians and Gynecologists, 2010; Royal College of Nursing, Sexual Health Competences, 2009; World Health Organization [WHO], 2011). As implemented in the United Kingdom, a coherent, evidencebased model of population-based and gender-sensitive care is delivered at the level of primary and specialty care.

In 2013, the Association of Reproductive Health Professionals convened a group of SRH experts from a wide range of educational, clinical, and policy backgrounds who came together to develop a shared agenda to address SRH workforce issues. At the outset, the participants agreed on fundamental tenets of SRH care: comprehensive SRH that includes care of women and men throughout the life cycle; public health prevention models to address health disparities; and team-based, interprofessional models of care. The expert group confirmed by consensus that there is a well-documented need for enhanced SRH training and education for all members of the healthcare team-particularly in primary care settings and in the context of the Patient Protection and Affordable Care Act (ACA; U.S. Department of Health and Human Services, 2011 ) implementation. To expand provision of SRH in primary care, the expert group proposed recommendations and defined next steps to align competency-based education for all healthcare professional students with both continuing professional development and service delivery within a primary care framework (Cappiello $\delta$ Nothnagle, 2013; Nothnagle, Cappiello, \& Taylor, 2013). Workgroups have continued to meet and develop action plans and proposals to enhance health professional education in SRH, implement quality measures and standards for SRH care, create incentives to expand and diversify the SRH workforce, and to create incentives to optimize patient access to care.

The gender/population oriented design and structure of the U.S. healthcare system attempts to address critical issues (i.e., cultural diversity, health disparities, social justice) in healthcare delivery, education, policy, and research while simultaneously being sensitive to the systems across practice settings. This can be daunting for most. There is much to do to align education, practice, and credentialing systems that integrate populations and specialty SRH care across settings. The Women's Health Expert Panel of the American Academy of Nursing would like to thank Ms. Quallich for raising her issues and creating a forum for further discussion of men and women's $\mathrm{SRH}$. The need is great... we urge our colleagues to join us in developing initiatives to promote high quality, ac- cessible SRH care (and a competent workforce) as the nation begins to implement the ACA.

Diana Taylor, Versie Johnson-Mallard, Judith Berg, Ellen Olshansky, Elizabeth Kostas-Polston, Nancy Woods, \& Joan Shaver

\section{References}

Andrist, L., \& MacPherson, K. (2001). Conceptual models for women's health research: Reclaiming menopause as an exemplar of nursing's contributions to feminist scholarship. Annual Review of Nursing Research, 19, 29-60.

APRN Joint Dialogue Group Report. (2008). Consensus model for APRN regulation: Licensure, accreditation, certification \& education. American Association of College of Nursing. www.aacn.nche.edu/education-resources/ APRN Report.pdf. Accessed March 21, 2014.

Berg, J. A., Taylor, D., \& Woods, N. F. (2013). Where are we today: Prioritizing women's health services and health policy. A report by the Women's Health Expert Panel of the American Academy of Nursing. Nursing Outlook, $61,5-15$.

Cappiello, J., \& Nothnagle, M. (2013). SRH Workforce Summit: Now is the time to bring sexual and reproductive health to primary care. Contraception Journal, 88, 210-212.

Faculty of Sexual and Reproductive Healthcare, Royal College of Obstetricians and Gynecologists. (2010). Training curriculum plan, London, UK. (See overview of 15 modules for each of the core competencies in the provision of SRH (basic, intermediate, advanced) and 8 sections on training processes and evaluation of competencies, retrieved from http://www.fsrh.org/pdfs/SpecialtySection 1 . pdf) Retrieved from http://www.fsrh.org/pages/Training_Curriculum_Plan. asp.

McBride, A. B. (1993). From gynecology to GYN-ecology: Developing a practice research agenda for women's health. Health Care for Women International, 14, 315-325.

Nothnagle, M., Cappiello, J., \& Taylor, D. (2013). Sexual and reproductive health workforce project: Overview and recommendations from the SRH Workforce Summit, January 2013. Contraception Journal, 88, 204-209.

Olesen, V., Taylor, D., Ruzek, S., \& Clarke, A. (1997). Strengths and strongholds in women's health research. In S. Ruzek, V. Olesen, \& A. Clarke (Eds.), Women's health: Complexities and differences (pp. 580-606). Columbus, OH: Ohio State University Press.

Pender, N. J. (1987). Health promotion in nursing practice. Norwalk, CT: Appleton, Century, Crofts.

Royal College of Nursing, Sexual Health Competences. (2009). An integrated career and competence framework for sexual and reproductive health nursing across the UK Royal College of Nursing. London, UK: Royal College of Nursing.

Shaver, J. (1985). A biopsychosocial view of health. Nursing Outlook, 33(4), 186-191.

Shaver, J., Olshansky, E., \& Woods, N. F. (2013). Women's health research agenda for the next decade. A report by the Women's Health Expert Panel of the American Academy of Nursing. Nursing Outlook, 61, 16-24.

Taylor, D., \& Woods, N. F. (1996). Changing women's health, changing nursing practice. Journal of Obstetric, Gynecologic, and Neonatal Nursing, 25, 791-802.

U.S. Department of Health and Human Services. (2011). Affordable care act ensures women receive preventive services at no additional cost. HHS Press Office: U.S. Department of Health and Human Services: Washington, DC. Retrieved from http://www.hhs.gov/news/press/wpllpres/08/20110801b.html.

Woods, N. F. (1994). The United States women's health research agenda: Analysis and critique. Western Institute of Nursing Research, 16, 467-479.

World Health Organization (WHO). (2011). Sexual and reproductive health core competencies in primary care: Attitudes, knowledge, ethics, human rights, leadership, management, teamwork, community work, education, counselling, clinical settings, service, provision. Geneva: World Health Organization, 2011. Retrieved from http://whqlibdoc.who.int/publications/2011/ 9789241501002_eng.pdf. 